\title{
NOTES
}

\section{Bending of Polyelectrolyte Membrane-Platinum Composites by Electric Stimuli I. Response Characteristics to Various Waveforms}

\author{
Kinji Asaka, Keisuke Oguro, Yasuo Nishimura, \\ Minoru Mizuhata, and Hiroyasu TaKenaKa \\ Osaka National Research Institute, AIST, 1-8-31, \\ Midorigaoka, Ikeda, Osaka 563, Japan.
}

(Received July 15, 1994)

\begin{abstract}
KEY WORDS Polyelectrolyte Membrane / Bending / Actuator / Polymer Gel / Electric Stimuli / Membrane-Platinum Composite / Charging Current /
\end{abstract}

Recently, considerable attention has been paid to the deformation of polymer gels in response to environmental changes. ${ }^{1}$ The deformation has potential applications for muscle-like actuators, such as that driven by electric stimuli since it can be controlled easily. ${ }^{1}$ However, for using polymer gels as electrically driven actuators, there are some disadvantages, i.e., slow response and high voltage that causes water electrolysis.

Previous papers ${ }^{2-4}$ reported that low voltage which does not cause water electrolysis between platinum electrodes on both sides of perfluorosulfonic ion-exchange membrane gives a quick bent of the film in aqueous solution. The electrically driven composite has a lot of features, such as soft operation, easy minitaturization, fast response, long life to work and low driving voltage. However, the characteristics of bending response to various factors and mechanisms of bending still remain unclear. In this paper, bending response to several electric stimuli was studied. The aim of the paper is to represent the bending response as a function of current. By using the function, bending response to any electric stimuli is capable of being estimated. Phenomenological modeling is the first step to a theoretical understanding of bending response, and a mechanism of bending considered from the model is proposed.

\section{EXPERIMENTAL}

\section{Preparation of the Composites}

After surface roughening by dry-brasting, both sides of a film of perfluorosulfonic acid (Nafion ${ }^{\circledR} 117$ by E. I. DuPont de Nemours and Co.) were chemically plated with platinum. ${ }^{5}$ Platinum ammine complex cation adsorbed in the film was reduced by sodium boron hydride in outer solution. The amount of platinum on the surface of the membrane was about $3 \mathrm{mg} \mathrm{cm}^{-2}$. The thickness of polymer electrolyte membrane is $185 \mu \mathrm{m}$ as received and $210 \mu \mathrm{m}$ in the wet state. Equivalent weight is 1100 and water uptake is $0.37 \mathrm{~g} \mathrm{H}_{2} \mathrm{O} / \mathrm{g}$ dry membrane. ${ }^{6}$

Measurement

Figure 1 shows the measurement system. The plated film was cut into a ribbon with a width of $1 \mathrm{~mm}$ and length of $15 \mathrm{~mm}$. The ribbon was supported vertically in various aqueous solutions and displacement of the free end ( $10 \mathrm{~mm}$ from the fixed point) of the ribbon was measured by a laser displacement meter (KEYENCE LC-2100/LC-2220). In consideration of refraction of light, the value measured 


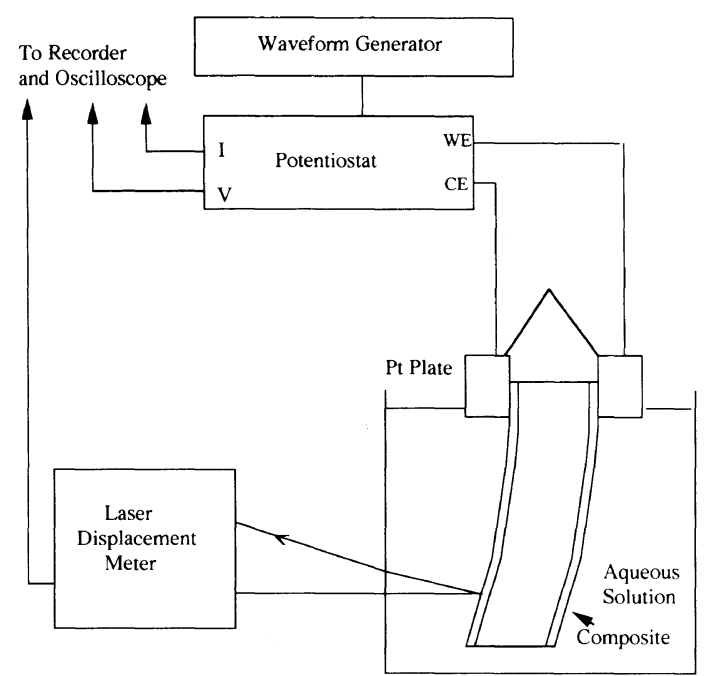

Figure 1. Layout of apparatus.

by laser displacement meter multiplied by 1.47 gives the compensated value for the refractive index. $^{2}$ The measured value in this paper is the compensated value. A voltage was measured with reference to the $\mathrm{CE}$ electrode and the sign of current flow from WE to CE electrode was a positive. All measured values were digitally sampled and recorded by Digital oscilloscope (Hitachi Denshi Ltd., VC-9145) and Digital recorder (Yokogawa Electric Co., ORM1200). The waveform generator and potentiostat/galvanostat used were an AG-1200 (Yokogawa Electric Co.) and HA-501G (Hokuto Denko Co.), respectively. All measurements were carried out at room temperature.

\section{RESULTS AND DISCUSSION}

Figures 2-4 show displacement and current response driven by step or sweep voltage in aqueous mixed solution consisting of $0.1 \mathrm{M}$ $\mathrm{Na}_{2} \mathrm{SO}_{4}$ and $10 \mathrm{mM} \mathrm{H}_{2} \mathrm{SO}_{4}$. The dotted lines in Figures 2-4 represent the displacement response curve calculated by the method as mentioned later. The current is the capacitive one in this voltage range, which does not cause water electrolysis.

In the case of step voltage, the composite
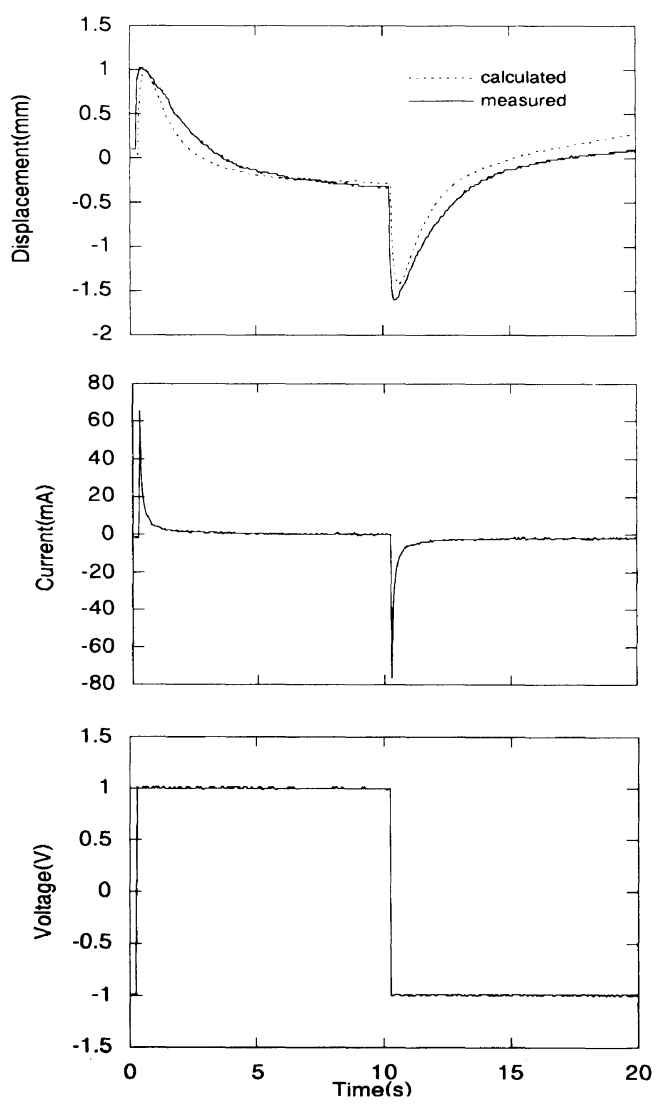

Figure 2. Displacement and current response driven by step voltage. The composite was immersed in a mixed solution consisting of $0.1 \mathrm{M} \mathrm{Na}_{2} \mathrm{SO}_{4}$ and $10 \mathrm{mM} \mathrm{H}_{2} \mathrm{SO}_{4}$.

quickly bends to the anode side and bends back to the cathode side gradually as shown in Figure 2. The displacement reached a peak value within $100 \mathrm{~ms}^{3,4}$ Triangular wave voltage of high sweep rate $\left(4 \mathrm{~V} \mathrm{~s}^{-1}\right)$ gave displacement proportional to the voltage as shown in Figure 3. In the case of triangular wave voltage of low sweep rate $\left(400 \mathrm{mV} \mathrm{s}^{-1}\right)$, the displacement waveform appeared similar to the current waveform rather than the voltage (Figure 4).

Figure 5 shows displacement and voltage response driven by square wave current in the same aqueous solution. The voltage varies gradually as the constant current charges or discharges electrodes. The displacement response $d(t)$ can be experimentally represented 

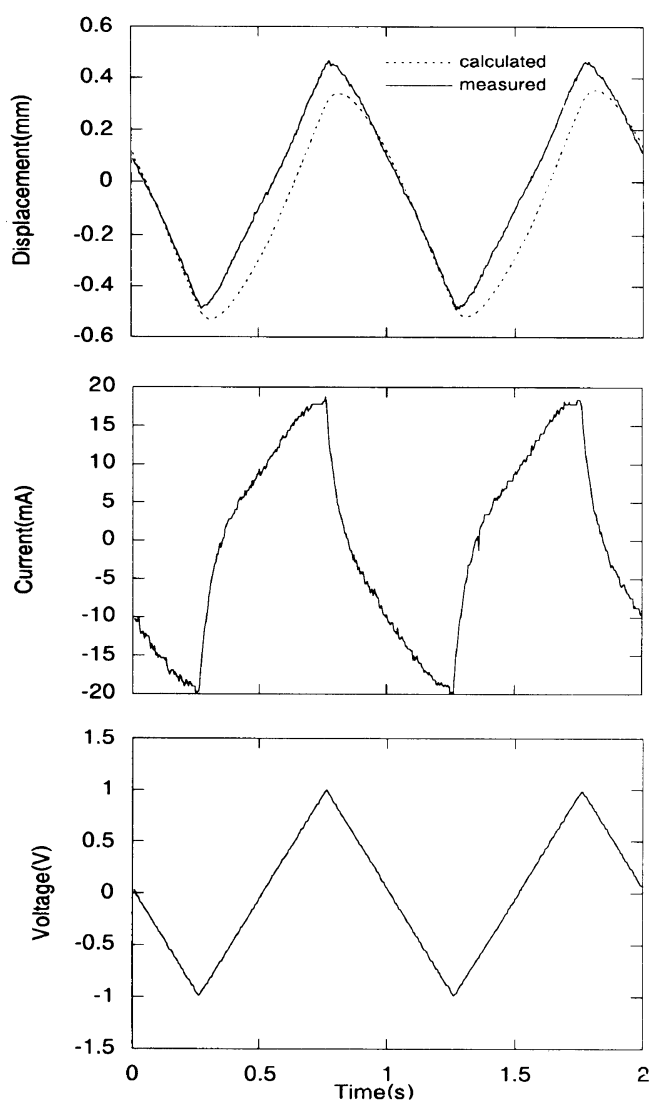

Figure 3. Displacement and current response driven by triangular voltage. The composite was immersed in a mixed solution consisting of $0.1 \mathrm{M} \mathrm{Na}_{2} \mathrm{SO}_{4}$ and $10 \mathrm{mM} \mathrm{H}_{2} \mathrm{SO}_{4}$. Sweep rate, $4 \mathrm{Vs}^{-1}$.

as a function of time $t$ as follows:

$$
d(t)=c_{1}\left(1-\exp \left(-\left(t-t_{\mathrm{s}}\right) / \tau\right)\right)+c_{2}\left(t-t_{\mathrm{s}}\right)+c_{3}
$$

where $c_{1}, c_{2}, c_{3}$ are constant values, $t_{\mathrm{s}}$ is the time when the sign of the square wave current changes, and $\tau$ is a time constant.

Preliminary experimental results show that displacement of different composites immersed in the same solution on application of the same voltage linearly depends on admittance of the composite. Therefore, displacement should be represented as a function of current rather than voltage, since the relation between displacement and current is simpler than that between displacement and voltage. Hence, on the basis
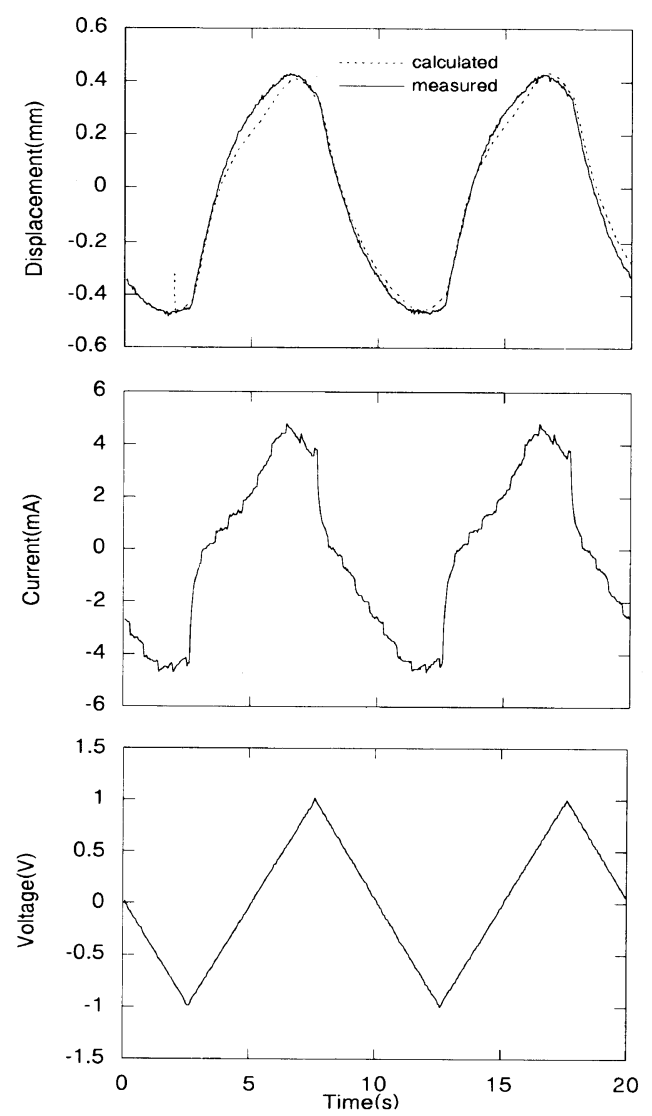

Figure 4. Displacement and current response driven by triangular voltage. The composite was immersed in a mixed solution consisting of $0.1 \mathrm{M} \mathrm{Na}_{2} \mathrm{SO}_{4}$ and $10 \mathrm{mM} \mathrm{H}_{2} \mathrm{SO}_{4}$. Sweep rate, $0.4 \mathrm{~V} \mathrm{~s}^{-1}$.

of the experimental results mentioned above, bending response is represented as a function of current flow between two electrodes, and a simple model is proposed for the bending of composites.

To generalize eq 1 , it is assumed that a superposition theorem can be applied to the relation between displacement response and current stimuli. The superposition theorem is that the response can be represented as a linearly additive function of stimuli history. The theorem can be applied to various phenomena and is called the "Curie-Hopkinson superposition theorem" in dielectrics ${ }^{7 a}$ and the "Boltzemann superposition theorem" in viscoelastic phenomena. ${ }^{7 b}$ By using the super- 

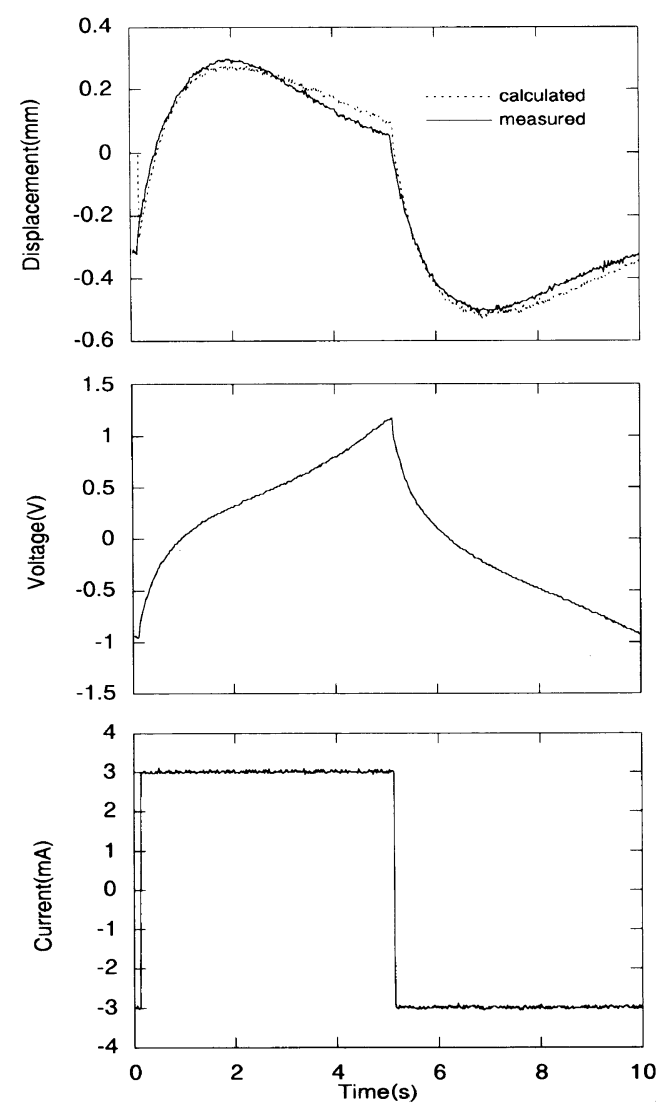

Figure 5. Displacement and voltage response driven by step current. The composite was immersed in a mixed solution consisting of $0.1 \mathrm{M} \mathrm{Na}_{2} \mathrm{SO}_{4}$ and $10 \mathrm{mM} \mathrm{H}_{2} \mathrm{SO}_{4}$.

position theorem, we obtain the following equation:

$$
\begin{aligned}
d(t)= & \int_{-\infty}^{t} k_{1} \exp (-(t-u) / \tau) i(u) \mathrm{d} u \\
& +\int_{-\infty}^{t} k_{2} i(u) \mathrm{d} u
\end{aligned}
$$

where $k_{1}, k_{2}$ are displacements per unit charge and $i(u)$ is current at time $u$. For simplicity, $k_{1}$, $k_{2}$ are assumed to be constant.

Let us consider the case that current $i(u)$ is a square waveform whose period $T$ is much longer than time constants $\tau$. If time $t_{0}$ satisfies the condition: $T>t_{0} \gg \tau$, and the square waveform current $i(u)$ switches from $-I$ to $I$ at time 0 , the integral constant $-\infty$ can be replaced by $-t_{0}$ in eq 2 , since the inequality:

$$
\begin{aligned}
& \int_{-\infty}^{-t_{0}} k_{1} \exp (-(t-u) / \tau) I \mathrm{~d} u \\
& \ll \int_{-t_{0}}^{t} k_{1} \exp (-(t-u) / \tau) I \mathrm{~d} u
\end{aligned}
$$

is satisfied. Hence we obtain the following equation:

$$
\begin{aligned}
d(t)= & -\int_{-t_{0}}^{0} k_{1} \exp (-(t-u) / \tau) I \mathrm{~d} u \\
& -\int_{-t_{0}}^{0} k_{2} I \mathrm{~d} u \\
& +\int_{0}^{t} k_{1} \exp (-(t-u) / \tau) I \mathrm{~d} u \\
& +\int_{0}^{t} k_{2} I \mathrm{~d} u+d\left(-t_{0}\right) \\
= & k_{1} I \tau-2 k_{1} I \tau \exp (-t / \tau)+k_{2} I t-k_{2} I t_{0} \\
& +d\left(-t_{0}\right) \\
= & 2 k_{1} I \tau(1-\exp (t / \tau))+k_{2} I t+d(0)
\end{aligned}
$$

where $d(0)$ and $d\left(-t_{0}\right)$ are displacement at time 0 and $-t_{0}$, respectively, and $d(0)$ is represented as $d(0)=-k_{1} I \tau-k_{2} I t_{0}+d\left(-t_{0}\right)$. Equation 3 is in conformity with eq 1 . By fitting the theoretical curve calculated by eq 3 to the measured curve, the parameters $k_{1}, k_{2}, \tau$ can be determined. The dotted line in Figure 5 shows the calculated curve.

To confirm the applicability of eq 2 , the displacement response driven by step or sweep voltage (Figures $2-4$ ) was calculated by using eq 2 from the parameters $k_{1}, k_{2}$ obtained by the step current measurement. Calculation was carried out by numerical computation, using the discrete form of eq 2 as follows:

$$
\begin{gathered}
d\left(n t_{\text {samp }}\right)=\sum_{j=0}^{n}\left[k_{1} \exp \left\{-t_{\text {samp }}(n-j) / \tau\right\} i_{j} t_{\text {samp }}\right. \\
\left.+k_{2} i_{j} t_{\text {samp }}\right]+d_{\text {off }} \\
(n=1,2,3,4, \cdots)
\end{gathered}
$$


where $t_{\text {samp }}$ is the sampling rate, $i_{j} j$ th sampled value of current and $d_{\text {off }}$ appropriate offset value of displacement. In the case of triangular waveform, $d$ with which the condition $n t_{\text {samp }}>3 \tau$ is fulfilled is adopted as the steady state one, which can be compared with experimental results. The dotted lines in Figures $2-4$ show the calculated curves, which are in good agreement with those measured.

Table I summarizes the parameter values obtained by square wave current measurement, together with those in aqueous solution of different $\mathrm{H}_{2} \mathrm{SO}_{4}$ concentrations. The results of voltage control measurements in aqueous solution of different $\mathrm{H}_{2} \mathrm{SO}_{4}$ concentrations can be simulated by the parameters in Table I, in the same manner as shown in Figures 2-4. The parameter $k_{1}$ is always positive, irrespective of $\mathrm{pH}$, while the parameter $k_{2}$ depends on $\mathrm{H}_{2} \mathrm{SO}_{4}$ concentration markedly and is negative in acidic solution.

In the case of cation-exchange membrane, coupled with charging current, ion flux and electro-osmotic drag of water flow from the anode to the cathode. ${ }^{8}$ It is therefore considered that the cathode side swells, the other side contracts, and the composite bends to the anode side. This process is accompanied by relaxation, i.e., water diffusion. The first term of eq 2 represents this situation.

Another mechanism of bending considered is as follows. It is considered that there is electric double layer at the interface between $\mathrm{Pt}$ electrode and polyelectrolyte membrane. Application of voltage between Pt electrode and polyelectrolyte membrane cause interfacial tension ${ }^{9}$ and ion concentration in the layer to change. Change in ion concentration means change in osmotic pressure. ${ }^{10}$ Application of voltage between two electrodes gives different interfacial tensions and osmotic pressures at each interface between the electrode and polyelectrolyte membrane. Bending stress is considered due to these differences. This mechanism is considered to have no relaxation process. The direction of bending stress de-
Table I. Parameter data

\begin{tabular}{|c|c|c|c|}
\hline $\mathrm{H}_{2} \mathrm{SO}_{4}$ Conc. & $k_{1}$ & $k_{2}$ & $\tau$ \\
\hline $\mathrm{mM}$ & $m C^{-1}$ & $\mathrm{mC}^{-1}$ & s \\
\hline 0 & 0.137 & 0.0631 & 0.79 \\
\hline 5 & 0.211 & -0.0163 & 0.75 \\
\hline 10 & 0.179 & -0.0236 & 0.67 \\
\hline 20 & 0.170 & -0.0396 & 0.73 \\
\hline 30 & 0.148 & -0.0382 & 0.72 \\
\hline
\end{tabular}

${ }^{a}$ The composite was immersed in a mixed aqueous solution consisting of $0.1 \mathrm{M} \mathrm{Na} \mathrm{NO}_{4}$ and $\mathrm{H}_{2} \mathrm{SO}_{4}$ of different concentrations.

pends on various factors. The second term of eq 2 may be due to the stress.

The characteristics of bending response depends on $\mathrm{pH}$ and salt concentration in aqueous solution, element in electrode, process of plating, composition of the polymer, and and others. The effects of these factors are being studied and the results will be reported soon.

\section{REFERENCES}

1. Y. Osada and J. Gong, Prog. Polym. Sci., 18, 187 (1993).

2. K. Oguro, Y. Kawami, and H. Takenaka, Bull. Gov. Ind. Res. Inst. Osaka, 43, 21 (1992) (in Japanese).

3. K. Oguro, Y. Kawami, and H. Takenaka, J. Micromachine Soc., 5, 27 (1992) (in Japanese).

4. K. Oguro, K. Asaka, and H. Takenaka, Proceedings, "4th International Symposium on Micro Machine and Human Science," Economic Affairs Bureau, Nagoya, 1993, p 38.

5. H. Takenaka, Soda to Enso (Soda and Chlorine), 37, 323 (1986) (in Japanese).

6. J. T. Hinatsu, M. Mizuhata, and T. Takenaka, $J$. Electrochem. Soc., 141, 1493 (1994).

7. (a) S. Oka and O. Nakata, "Kotai Yuudentairon (Theory of Solid Dielectrics)," Iwanami Shoten, Tokyo, 1960 (in Japanese); (b) J. D. Ferry, "Viscoelastic Properties of Polymers," John Wiley \& Sons, Inc., New York, N.Y., 1970.

8. T. A. Zawodzinski, Jr., C. Derouin, S. Radzinski, R. J. Sherman, V. T. Smith, T. E. Springer, and S. Gottesfeld, J. Electrochem. Soc., 140, 1041 (1993).

9. T. R. Beck and K-F. Lin, J. Electrochem. Soc., 126, 252 (1979).

10. P. J. Flory, "Principles of Polymer Chemistry," Cornell University Press, Ithaca, N.Y., 1953. 